\title{
Learning Model Based on Multiple Intelligence in Stimulating Musical Intelligence in Children
}

\author{
Anada Leo Virganta ${ }^{1}$, Kamtini ${ }^{2}$, Nurmaniah ${ }^{3}$, Salsabila Hasiana Tanjung ${ }^{4}$ \\ ${ }_{1,2,3}$ Universitas Negeri Medan, Indonesia \\ ${ }^{4}$ Universitas Negeri Yogyakarta, Indonesia \\ lanadaleovirganta@unimed.ac.id,kamtini@unimed.ac.id,nurmaniah@unimed.ac.id, \\ hasianasalsabila@gmail.com
}

\begin{abstract}
Every child has different characteristics with different ways of learning. Children tend to have a very active nature because they have seen muscle development that allows them to perform a variety of skills. By using learning based on multiple intelligence, children are more stimulated to carry out the learning process and significant development achievements are achieved. This study uses a development research method by conducting time-series tests on data processing. The population used is children aged five to six who are in kindergarten age, namely children aged in five until six years. Children show a good increase in the stimulation of musical intelligence using a learning model that has been developed. The novelty of this research is to produce and use a learning model based on multiple intelligences that children have. But still, focus on stimulating children's musical intelligence.
\end{abstract}

Keywords multiple intelligence; musical; children

\section{Introduction}

Early Childhood Education is a coaching effort aimed at children from birth up to the age of six which is carried out through providing educational stimuli to assist physical and spiritual growth and development so that children have readiness to enter further education, according to Law Number 20 of 2003 about the National Education System. Through simple sports activities, children can develop other intellectuals. Early childhood is a golden age or often called the golden age which is usually marked by rapid changes in physical, cognitive, social and emotional development (Mashburn, LoCasale-Crouch and Pears: 2018). Education for early childhood is a fun education with the principle of learning through play. Starting from this, learning for early childhood must be observed, so that developmental achievements and learning objectives can be achieved significantly.

One of the intelligences that has an important role in life is musical intelligence. As with other intelligences, Musical intelligence needs to get a stimulus or stimulus and opportunity with the environment to develop (Lozy, Holmes and Donaldson: 2020). Musical intelligence can be said to be one of the intelligences that children must have. Musical Intelligence is the ability to combine physical and mental powers to produce perfect movements. Judging from the context of children, this perfect movement is easier to train or develop from an early age, because at an early age the physical development of children is experiencing good growth and their brain is still developing rapidly.

Every child has different characteristics with different ways of learning, of course. Children tend to be very active because they have seen muscle development that allows them to perform various skills (Respati and Elissolihati: 2017). Apart from different 
personal characteristics, children also have different intelligence. So it is very appropriate if the learning model given to children adopts the play while learning approach or vice versa, namely learning while playing. This is because through playing, children are expected to be able to carry out various types of skills that they like in a fun way according to their age who really like playing.

Learning for early childhood must be in accordance with the characteristics that exist in children, including some of the intelligence that children have. Included in learning that stimulates musical intelligence in children. Providing learning to stimulate children's musicals also requires a learning model that is in accordance with the child's intelligence. Based on this, researchers are interested in developing Multiple Intelligence-Based Learning Models in Stimulating Musical Intelligence in 5-6 Years Old Children in Medan City. The hypothesis of the implementation of this study will contribute to musical learning in children aged 5-6 years.

The research objectives of the implementation of this research are to find out how musical intelligence can be achieved in children aged 5-6 years, to produce a multiple intelligence-based learning model in stimulating musical intelligence of children aged 5-6 years, to determine the effectiveness of developing multiple intelligence-based learning in stimulating musical intelligence of children aged 5-6 years.

\section{Review of Literatures}

The learning model has objectives in its implementation in the process of learning activities for children (Arends, 2001: 7; Joyce, Weil and Shower, 1992: 13-16). Learning objectives will affect how the concept of implementing the learning model is used. The learning model is analyzed by an operational model that characterizes the existence of a syntax or sequence of learning activities, social systems or roles and relationships between students and teachers, the principle of reaction or how the teacher responds to and responds to children's behavior and support systems, namely the requirements and support needed in carrying out learning. Providing appropriate learning for children can produce good achievement for children (Dunlosky, Rawson, Marsh, Nathan, Willingham, 2013: 5). Children will feel comfortable and make sense of the learning activity process given. The most important thing in using learning models for children is the play aspect in the implementation of learning (Farrington, 2017: 28). Other components that are important in the learning model are the objectives and assumptions of using the learning model and the impact of learning for children in accordance with the learning plan using the learning model used. The principles of project-based learning are also based on constructive learning theory. Constructive learning has to do with cultivating students' efforts to construct complex and rich representations of memory, which demonstrate a strong degree of relationship between semantic, episodic, and action knowledge (Simanjuntak, 2020).

The syntax in the learning model is the first component that contains the learning steps which in this study are written based on the needs of the researcher and adapted to classroom conditions. The use of the learning model also views the principle of reaction related to how teachers care for and treat children (Joyce \& Weil, 1992: 15). The reaction principle in the learning model assesses how teachers and children respond to each other such as asking questions and answering questions and responding to any behavior that appears in the learning process.

The principles of the social system in the learning model see how children are active in learning and teachers play an active role as facilitators in implementing the learning 
model. Children can become active learners when given activities that encourage children to move a lot (Gehris, Gooze and Whitsker, 2015: 125). Children can carry out each task given in the learning activity to take place, children are free to do and complete the tasks given and get their own learning experience but within the limits of the learning principles set by the teacher. In the learning process the teacher creates a learning environment that motivates children to interact that is conducive to learning activities. Learning experiences obtained by children are the result of exploration, reflection, thinking and finally the children act again according to the activities given (Sato, 2016: 6). Children will behave and have skills based on the experiences that children get through learning activities given to children.

Developing a learning model with the process of implementing the idea through the trial and evaluation stage to the development of the model according to the learning needs in terms of the aspects of the teacher, child and the material provided Teachers play an important role in supporting children to achieve their thinking skills (Housnan, 2014: 295; Clouston, et all, 2010: 9). Understand the situation before learning, which is in the form of learning using a learning model that has been developed and an analysis that links the results of understanding the hypothetical situation with the results of understanding after being given the behavior.

Intelligence can be estimated and classified based on intelligence tests. Intelligence measurement figure Alfred Binet said that intelligence is an ability consisting of three components (Teive, Teive, Dallabrida and Gutierrez: 2017), namely (1) the ability to direct thoughts or actions, (2) the ability to change the direction of thoughts or actions, and (3) the ability to criticize one's own thoughts and actions or autocritism. According to him, intelligence is something that is functional so that the level of individual development can be observed and assessed based on certain criteria. Whether a child is intelligent enough or not can be judged based on observations of how and the child's ability to take action and the ability to change the course of action if necessary.

Howard Gardner then gave rise to the term multiple intelligences. This term is then developed into theory through complex research, involving anthropology, cognitive psychology, developmental psychology, psychometry, biographical studies, animal physiology, and neuroanatomy (Gardner: 2018).

Intelligence, according to the multiple intelligences paradigm (Gardner: 2018), can be defined as an ability that has three main components, namely:

a. The ability to solve problems that occur in real life everyday;

b. Ability to generate new problems faced to be resolved;

c. The ability to create something or offer a service that will create respect in one's culture.

All these abilities are owned by all humans, even though humans have different ways of showing them.

Children's intelligence is also based on the main views of the multiple intelligences theory as follows.

a. Each child has the capacity to have nine intelligences. There are intelligences that can be highly developed, moderately developed, and underdeveloped.

b. All children, in general, can develop every intelligence to an adequate level of mastery if they receive sufficient support, enrichment, and teaching.

c. Intelligence works together in everyday activities. Children who sing need musical and musical intelligence.

d. Children have various ways to show intelligence in each category. The child may not be very good at jumping but able to resonate well (Musical intelligence), or does not like to tell stories, but quickly understands when spoken to (linguistic intelligence). 
According to Gardner, intelligence in multiple intelligences includes verballinguistic intelligence (word smart), logical-mathematical intelligence (numerical intelligence), visual-spatial intelligence (color-image intelligence), musical intelligence (music-song intelligence), kinesthetic intelligence (movement intelligence), interpersonal intelligence (social intelligence), intrapersonal intelligence (self-intelligent), and naturalist intelligence (natural intelligence), and existential intelligence (essence intelligence) (Gardner: 2018). Every intelligence in multiple intelligences has certain indicators. Children's multiple intelligence is identified through observation of behavior, actions, tendency to act, children's sensitivity to something, prominent abilities, spontaneous reactions, attitudes, and pleasure.

According to Khairani (2020) thinking skills are a gift that God has given us to always be grateful for all that He has created. Nur (2011: 7) states that "thinking is a person's ability to analyze, criticize, and formulate conclusions based on careful consideration. Critical thinking skills can be developed through science learning, precisely in elementary schools which focuses on systems, structures, concepts, principles, and tight ties between one element and another (Maulana, 2008: 39). Furthermore, Johnson (2007: 189 ) found that critical thinking is a hobby of thinking that can be developed by everyone, so this must be taught or applied since elementary school. Thinking skills stated by Iskandar (2009: 86-87) are reflective, critical, and creative reasoning activities that are oriented towards an intellectual which involves the formation of concepts, applications, analysis, synthesis or those resulting from observation, experience, reflection, communication as foundation of a belief (belief) and action.

Children who have musical intelligence can be characterized by the ability to create and appreciate rhythmic patterns of pitch and color. Children who have musical intelligence also have the ability to appreciate forms of musical expression (Al-Anani and Al Masri: 2020). Someone who is optimal in this intelligence tends to like and be effective in composing / composing melodies and lyrics, singing small, singing and whistling. They are also easy to recognize rhythm, easy to learn / remember rhythm and lyrics, like to listen to and appreciate music, play musical instruments, recognize instrument sounds, are able to read music, tap hands and feet, and understand musical structures.

In general, young children really like to play. Through play they learn, move and make music. These activities develop both motor skills. The development of small motor skills can be found in playing musical instruments that use a lot of fingers; while his major motor skills are developed when he sings while dancing or playing music together while marching or forming formations. In addition to playing music as well as developing other sensormotor sensitivities, such as when a child plays a small glokenspiel, he must coordinate his eyes and hands. Looking for the blades that will be hit with the sense of sight and the right hitting motion on the desired blade with his skill to hold the stick (bat) and hit it on the selected blade.

Information about musical intelligence in children can be obtained through observations of:

a. Their enjoyment and ability to sing and memorize songs, whistle, hum, and tap objects to make rhythmic sounds;

b. Their sensitivity and ability to perceive tones, rhythms, and ability to adapt sounds to accompanying notes;

c. Musical tendencies when children speak and their voices are melodic when singing;

d. Their enjoyment and ability to play musical instruments;

e. Their ability to recognize various types of sounds around them, ranging from human voices, machines, animals, and other distinctive sounds. 
Almost all children have this intelligence, and the best way to learn for them is with tone, rhythm, and melody (Swamianathan, Schellenberg and Khalil: 2017). Therefore, teachers need to facilitate children to be able to express themselves musically through rhythmic greetings, recitations, joint singing, pitched clapping, and, if possible, canned orchestras, and practice to distinguish between sounds and sounds around them.

\section{Research Method}

This research uses descriptive quantitative methods. This study aims to develop a multiple intelligence-based learning model to stimulate musical intelligence of children aged 5-6 years. Children are given learning activities that are in accordance with the type of multiple intelligence which in these activities can stimulate children's Musical intelligence.

Educational research and development is a development model whose results are used to design new products and procedures, which are then systematically tested, evaluated and processed until they meet certain criteria so that their effectiveness, quality, or standards are the same as other products related to developing products that are effective in learning.

The stages of implementing the research and development proposed by Borg and Gall can be grouped into three stages, namely Stage 1: a preliminary study of research and information collecting. Stage 2: product development, includes two activities: (a) planning and (b) developing a preliminary form of product. Stage 3: product validation includes seven activities: (a) preliminary field testing, (b) main product revision, (c) main field testing, (d) operational product revision, (e) operational field testing, (f) final product revision, (g) dissemination and implementation. The grouping of the research stages into three stages is only to facilitate the research process, in no way reduces the actual meaning of each step.

In this study, data collection techniques were carried out by observing the tests carried out by children. The data are quantitative in nature and are time series data. The data analysis used is a quantitative test in the form of a time series regression analysis test to see how big the effect is to see changes in child development from each given treatment.

Observations made in this study also aim to determine the effectiveness of model development on children's musical intelligence. Researchers observed children's abilities in carrying out learning activities that included multiple intelligence so that they could stimulate children's musical intelligence.

The data collection instrument used in this study was used to determine the initial data as a material for developing a model in accordance with the needs in the field. The instrument is also used for the process of collecting data about the feasibility and effectiveness of the developed model development.

A score scale is an instrument that requires observers to assign subjects to categories by giving ratings to those categories. The value scale used in this research and development uses a Likert scale. With this type of measurement scale, a firm answer will be obtained, namely the values with a scale of 1-4.

How to use the value scale, namely, when symptoms or elements appear as contained in the data classification, the expert and teacher give a check mark $(\sqrt{ })$ in columns 1-4 that match the criteria in the aspect to be assessed. 


\subsection{Results}

\section{Results and Discussion}

This research was conducted using a development model. Based on this, the research has conducted a preliminary study stage. In the process of conducting a preliminary study, researchers obtained data by conducting interviews with teachers that to improve Musical intelligence, the teacher's children had not used a specific or specific learning model to achieve and perform the intended stimulation. Based on the needs analysis stage, teachers need a learning innovation in the form of a model that can be used specifically to stimulate Musical intelligence but still pay attention to other development achievements.

Based on this, formulate the needs analysis data that has been obtained to plan a model that is in accordance with the needs of implementing learning in schools. The next researcher compiled the concept of model development according to the characteristics of the child's age and achievements in musical intelligence and multiple intelligence-based learning. Furthermore, researchers develop based on the results of needs analysis and conceptual planning and prepare learning tools needed in implementing the development model.

The next stage is to conduct development tests in preliminary field testing on a school of 30 children. The research was conducted in four trials using learning tools that are used to support the learning model that has been developed.

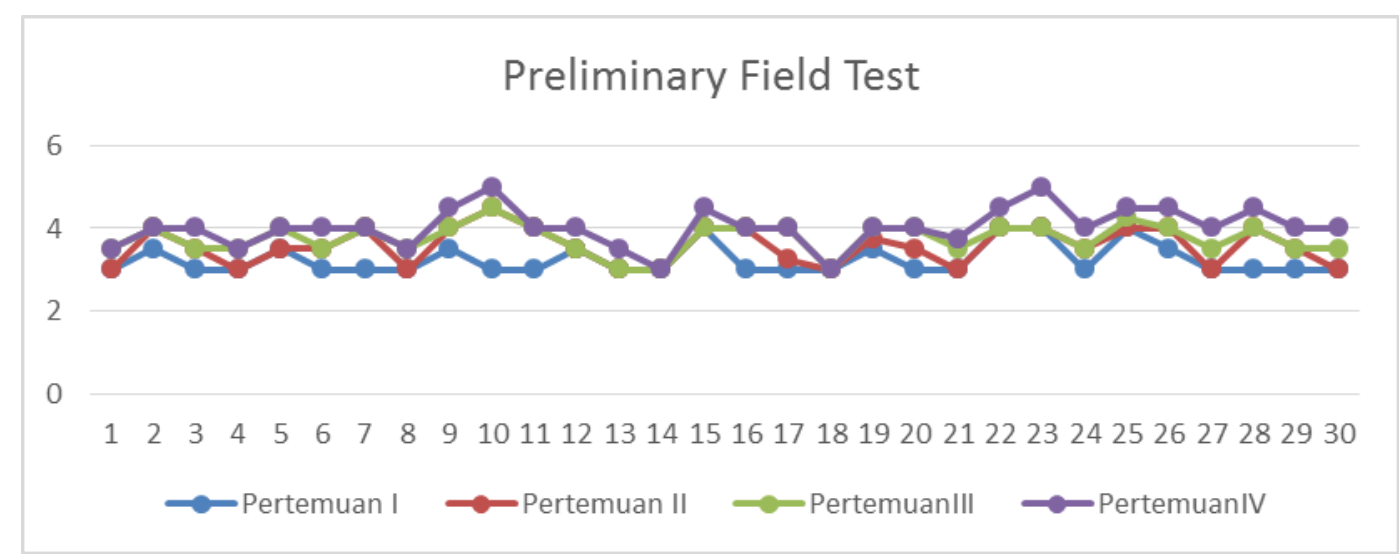

Graph I. Stages of Musical Intelligence Achievement with Development Model Preliminary Field Test

Based on Graph I, it can be seen that the musical intelligence achievements of children from stage I to IV have significant changes. There is an increase in the achievement of the stimulus according to the indicators used in measuring children's musical intelligence. Each child has increased the graph from each research implementation carried out. Children feel happy in the learning process. Activities carried out by children are carried out in a fun way and the intended results are achieved according to the research implementation plan.

In accordance with the implementation at the initial stage of implementation or at the Preliminary Field stage, there are several things that must be revised. These things are like the learning tools used in the form of the main rhythmic musical instrument which need to be enlarged in size and using supporting learning tools with basic colors such as red, blue and yellow. In addition, using simple rhythmic musical instruments such as wooden sticks as a complement to the learning tools used. 
After the revision process is carried out, the product is tested at the main field testing stage using four stages of product testing.

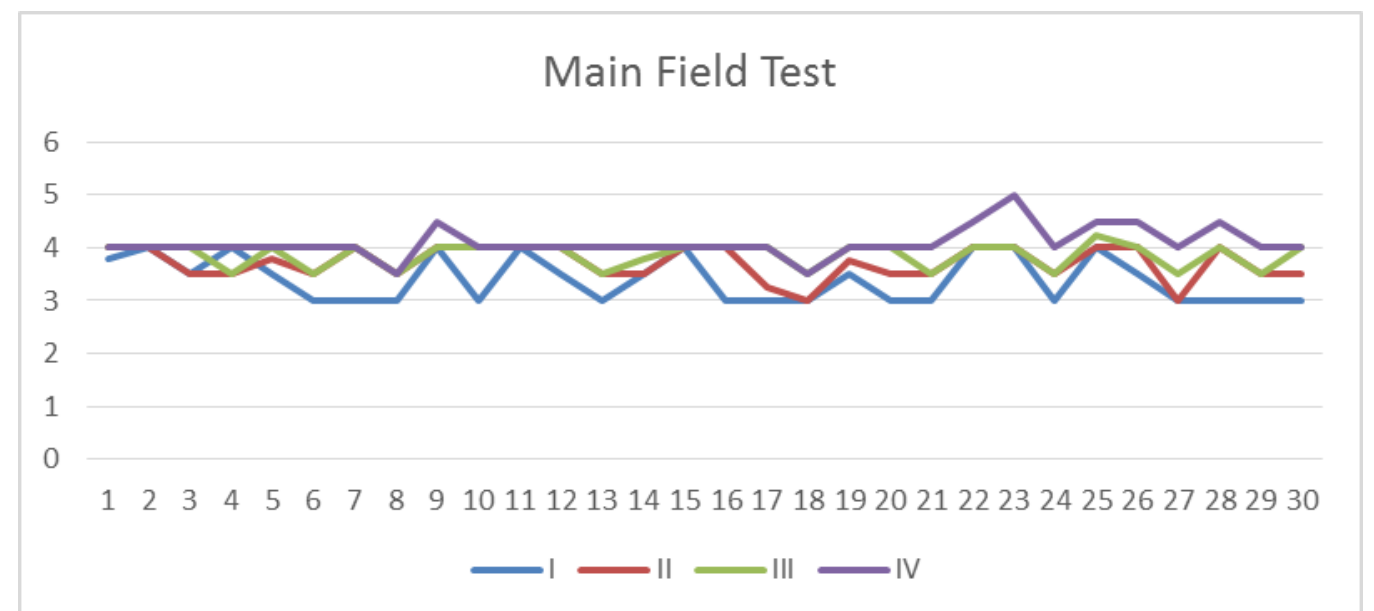

Graph II. Stages of Achievement of Musical Intelligence with the Main Field Test Development Model

Based on Figure II, it can be seen that the musical intelligence achievements of children from stage I to IV have significant changes. When compared with the values in Graph I, there is a significant change in the children's achievements in using the applied model. There is an increase in the achievement of the stimulus according to the indicators used in measuring children's musical intelligence. Each child has increased the graph from each research implementation carried out.

After the implementation of the main field test, several things need to be improved. Namely using a musical rhythm pattern that is easier for children to follow. It is like a rhythm pattern indicating moving forward and a rhythm pattern indicating moving sideways.

The final implementation of the operational field test is by applying a learning model based on the last revision product.

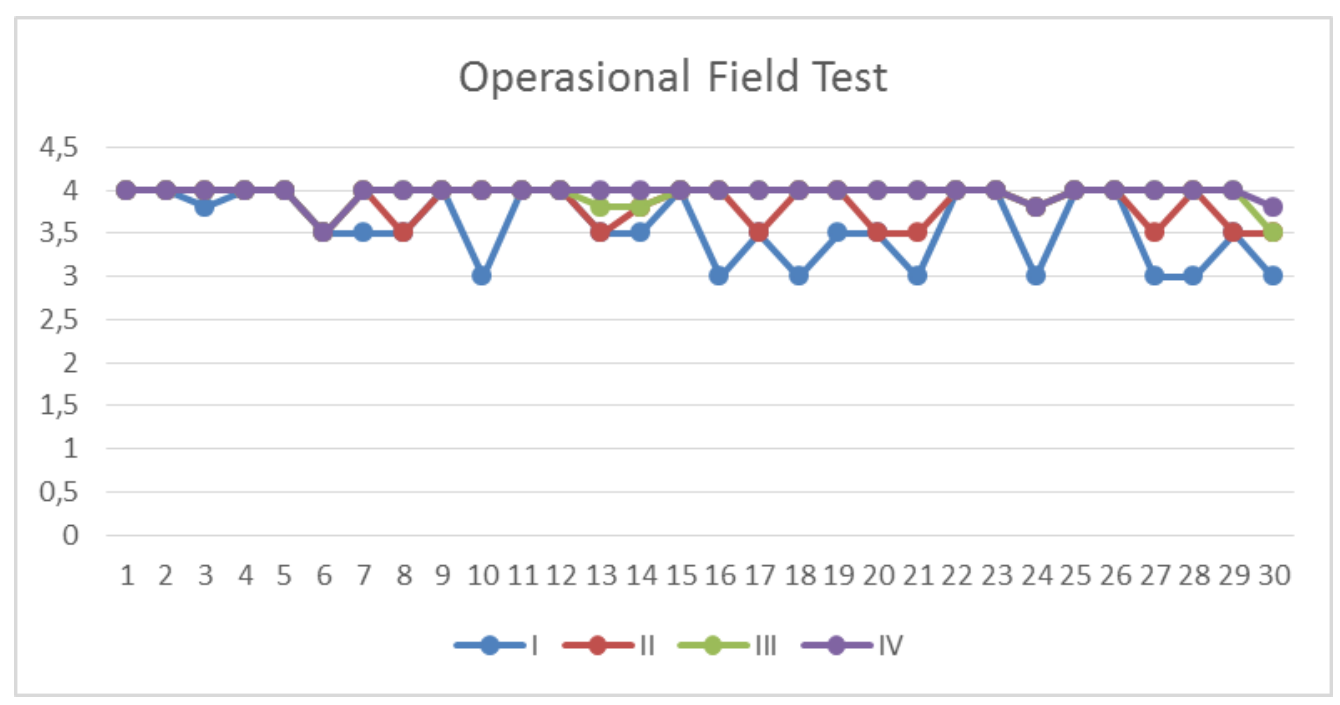

Graph III. Stages of Achievement of Musical Intelligence with a Development Model Operational Field Test 
Based on the results of the operational test in graph III, each child at the fourth meeting obtained almost perfect performance on the scale that had been determined in each assessment indicator on the child's musical intelligence. There are only a few children who have not reached the perfect scale but exceed the scores in the good category.

When compared with the previous treatment test, then in the model treatment in the operational test, it can be stated that there are significant changes from the treatment given. This is also influenced by the implementation of the model that has been adjusted to the revisions that have been implemented.

\section{Conclusion}

Research on the development of multiple intelligence-based learning models in stimulating musical intelligence in children aged 5-6 years fulfills needs based on a needs analysis carried out in schools. Children who have musical intelligence need the right stimulus to learn while playing music, and master movements in the preparation stage and music performance. Through play they learn, move and make music. These activities develop both motor skills. The development of small motor skills can be found in playing a more dominant musical instrument using fingers such as pianica; while his major motor skills are developed when he sings while dancing or playing music together while marching or forming formations. In addition to playing music as well as developing other sensormotor sensitivities, such as when a child plays a small glokenspiel, he must coordinate his eyes and hands. Looking for the blades that will be hit with the sense of sight and the right hitting motion on the desired blade with his skill to hold the stick (bat) and hit it on the selected blade.

The stimulation of musical intelligence stimulates the development and growth of children. In accordance with the nature of the child, namely like to move, the learning process should pay attention to this tendency. Children with this intellectual tendency learn by listening, touching, manipulating, and moving. They need learning activities that are musical and dynamic. They need access to a music laboratory with adequate and safe musical instruments for use by children. Intelligence in multiple intelligences includes verbal-linguistic intelligence (word smart), logical-mathematical intelligence (numerical intelligence), visual-spatial intelligence (color-image smart), musical intelligence (musicsong smart), kinesthetic intelligence (motion smart), interpersonal intelligence (social intelligence), intrapersonal intelligence (self-intelligent), naturalist intelligence (natural intelligence), existential intelligence (essence intelligence). Every intelligence in multiple intelligences has certain indicators. Children's multiple intelligence is identified through observation of behavior, actions, tendency to act, children's sensitivity to something, prominent abilities, spontaneous reactions, attitudes, and pleasure. As a model that stimulates musical intelligence, in the use of multiple intelligence-based models, there is stimulation in the dominance of musical intelligence, but there are still things related to stimulation of other multiple intelligences.

The effectiveness of developing multiple intelligence-based learning models in stimulating musical intelligence of children aged 5-6 years has a positive effectiveness for the achievement of children's musical intelligence. Based on the development test conducted, the child experienced an increase in achievement from each test meeting that was conducted. 


\section{References}

Al - Anani, H. A. H., \& Al Masri, A. A. 2020. The Effectiveness of a Training Program in

Developing the Linguistic and Musical Intelligence among University Students. International Journal of Learning, Teaching and Educational Research, 18 (12).

Arends, R.I. 2001. Learning to teach. New York: Mc Graw Hill Companies, Inc.

Dunlosky, John. Rawson, Katherine A. Marsh, Elizabeth J. Nathan, Mitchell J. Willingham, D T. 2013. Improving students' learning with effective learning techniques: promising directions from cognitive and educational psychology. psychological science.

http:/journals.sagepub.com/doi/abs/10.1177/1529100612453266

Farrington, D. P. 2017. A developmental model of the propensity to offend during childhood and adolescence. In Integrated developmental and life-course theories of offending (pp. 25-60). Routledge.

Gardner, H. 2018. Multiple approaches to understanding. In Contemporary Theories of

Khairani, S., Suyanti, R.D., and Saragi, D. (2020). The Influence of Problem Based Learning (PBL) Model Collaborative and Learning Motivation Based on Students' Critical Thinking Ability Science Subjects in Class V State Elementary School 105390 Island Image. Budapest International Research and Critics in Linguistics and Education (BirLE) Journal Vol 3 (3): 1581-1590.

Learning (pp. 129-138). Routledge.

Gehris, J. S., Gooze, R. A., \& Whitaker, R. C. 2015. Teachers' perceptions about children's movement and learning in early childhood education programs. Child: care, health and development, 41 (1), 122-131. https://doi.org/10.1111/cch.12136

Housnan. 2014. Pendekatan saintifik dan kontekstual dalam pembelajaran abad 21 kunci sukses implementasi kurikulum 2013. Bogor: Ghalia Indonesia.

Joyce, B., Weil, M., and Shower, B. 1992. Models of teaching. Massachusetts: Allyn and Bacon.

Mashburn, A. J., LoCasale-Crouch, J., \& Pears, K. C. (Eds.). 2018. Kindergarten Transition and Readiness: Promoting Cognitive, Social-Emotional, and SelfRegulatory Development. Springer.

Respati, R., \& ElisSsolihati, T. S. U. 2017. Motion in song as efforts to increase Intelligence kinesthetic early childhood. saung-guru, 527.

Sato, Aiko. Haan, Jonathan de. 2016. Applying an experiential learning model to the teaching of gateway strategy board games. International Journal of Instruction. http://www.e-iji.net/dosyalar/iji_2016_1_1.pdf

Simanjuntak, L., Sriadhi, and Saragi, D. (2020). The Effect of Project Based Learning Models and Learning Motivation on Civics Learning Results in 4th Grade Primary School 106163 Percut Sei Tuan. Budapest International Research and Critics in Linguistics and Education (BirLE) Journal Vol 3 (3): 1509-1520.

Swaminathan, S., Schellenberg, E. G., \& Khalil, S. 2017. Revisiting the association between music lessons and intelligence: Training effects or music aptitude?. Intelligence, 62

Teive, H. A., Teive, G. M., Dallabrida, N., \& Gutierrez, L. 2017. Alfred Binet: Charcot's pupil, a neuropsychologist and a pioneer in intelligence testing. Arquivos de neuropsiquiatria, 75(9), 673-675. 